\title{
Penerapan algorithma $k$-mean untuk clustering data obat pada puskesmas rumbai
}

\author{
Taslim $^{1}$, Fajrizal $^{2}$ \\ ${ }^{12}$ Program Studi Teknik Informatika, Universitas Lancang Kuning, Pekanbaru \\ Jl. Yos Sudarso KM 8 Rumbai, Pekanbaru \\ E-mail: 'taslim.malano@gmail.com, ${ }^{2}$ Fajrizal@unilak.ac.id
}

\begin{abstract}
Abstrak
Melalui program jaminan kesehatan pemerintah berupaya terus menjamin kesehatan bagi masyarakat melalui puskesmas puskesmas atau balai pengobatan. Salah satu komponen yang sangat penting pada puskesmas maupun balai pengobatan adalah masalah ketersediaan obat. Ketersediaan obat harus dikelola secara baik untuk menjamin obat yang dibutuhkan oleh masyarakat selalu tersedia dengan jumlah yang cukup dan memadai. Clusterisasi pada data mining dapat digunakan untuk menganalisa pemakaian obat yang terjadi selama ini pada sebuah puskesmas untuk digunakan sebagai salah satu alat bantu penunjang keputusan bagi pihak puskesmas untuk mengajukan permintaan obat pada periode yang akan datang. Hasil dari penelitian ini dapat mengelompokkan tingkat pemakaian obat pada apotik puskesmas Rumbai Bukit Pekanbaru
\end{abstract}

Kata Kunci : Data mining, k-means, obat, puskesmas, cluster

\begin{abstract}
Abstrack
Through the government health insurance program seeks to continue to ensure public health through public health centers health centers or clinics. One very important component in health centers and clinics is the issue of availability of drugs. Availability of the drug should be managed properly to ensure the drug is needed by the community always available in sufficient quantities and adequate. Clusterisasi on data mining can be used to analyze the use of drugs that occurred during this time in a health clinic to be used as a decision support tool for the clinic to request the drug in the coming period. The results of this research can classify the level of drug use at the health center pharmacy Tassel Hill Pekanbaru
\end{abstract}

Keyword: Data mining, k-means, medicine, health centers, cluster

\section{Pendahuluan}

Obat merupakan salah satu komponen yang penting dalam hal kesehatan baik untuk mencegah, mengurangi, menghilangkan atau menyembuhkan suatu penyakit atau gejala penyakit. Untuk itu obat perlu dikelola dengan baik, efektif dan efisien. Perencanaan kebutuhan obat merupakan hal yang penting dilakukan untuk menjamin ketersediann dan pemerataan obat dengan jenis dan jumlah yang mencukupi agar obat dapat diperoleh dengan cepat pada tempat dan waktu yang tepat pada instansi instansi yang terkait dengan pelayanan kesehatan, baik itu rumah sakit, puskesmas, dinas kesehatan dan lain sebagainya. Perencanaan kebutuhan obat akan mempengaruhi pengadaan, pendistribusian dan dan pemakaian obat di tempat pelayanan kesehatan

Clusterisasi kebutuhan obat diharapkan dapat menjadi salah satu sumber pengambilan keputusan untuk menjamin ketersediaan obat pada dinas kesehatan Kota Pekanbaru. Clustering data merupakan salah satu metoda dalam data mining yang dapat digunakan untuk memetakan data kedalam kelompok kelompok yang lebih kecil berdasarkan kesamaan karakateristik yang dimilikinya (Perim, Wandekokem, \& Varejão, 2008). Dengan hasil clustering ini distribusi obat 
pada instansi layanan kesehatan dapat dikelompokkan sesuai kebutuhan berdasarkan data distribusi obat pada tahun tahun sebelumnya dan dapat digunakan sebagai acuan perencanaan obat untuk tahun berikutnya. Dengan begitu diharapkan ketersediaan obat untuk tahun berikutnya dapat lebih terjamin dan dapat memenuhi permintaan permintaan obat dari instansi instansi layanan kesehatan.

Salah satu metoda clustering yang paling terkenal diantara algorithma clustering yaitu Kmeans (Patel \& Mehta, 2011). Kesederhanaan metode ini membuat algorithma K-means dapat diaplikasikan pada berbagai bidang (K.Arai and A.R. Barakbah, 2007).

\section{Metode Penelitian}

\subsection{Tahapan tahapan dalam data mining}

KDD adalah proses nontrivial mengidentifikasi validitas data, potensi, guna, dan akhirnya menghasilkan pola data yang dapat dimengerti (Daniel t. larose 2007). Adapun tahapan tahapan dalam data mining yaitu :

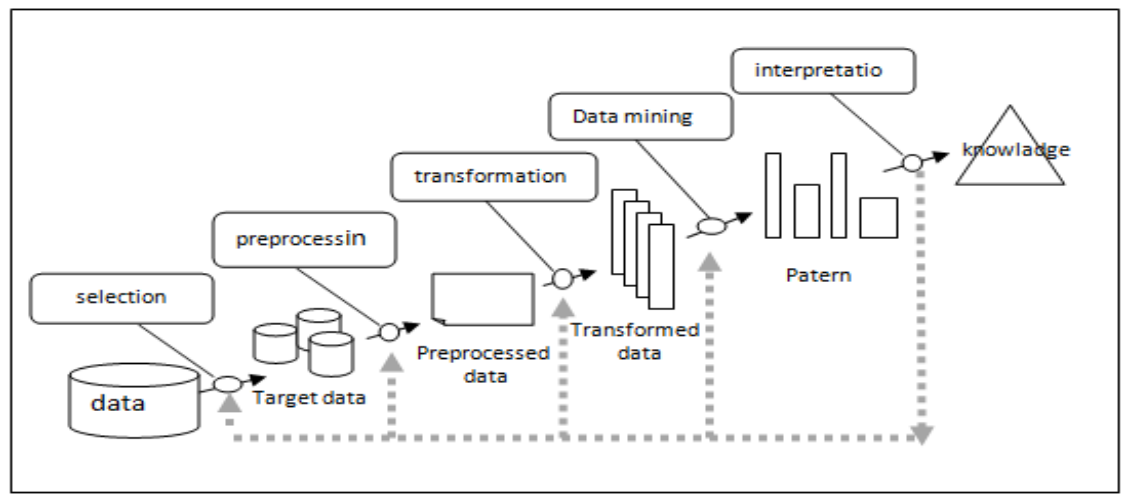

Gambar 1. Tahapan tahapan pada data mining

Pada penelitian ini digunakan data yang berasal dari Laporan Pemakaian dan Lembar Permintaan Obat (LPLPO) Puskesmas Rumbai Bukit tahun 2014. Selanjutnya dilakukan proses clustering terhadap data yang ada untuk mendapatkan pola kebutuhan obat untuk masyarakat wilayah Rumbai Pekanbaru.

\subsection{Clustering}

Clustering mengacu pada pengelompokan catatan, observasi, atau kasus ke dalam kelas yang serupa. Sebuah cluster adalah kumpulan dari catatan yang mirip satu sama lain dan berbeda dengan catatan dalam cluster lain. Clustering berbeda dengan classification yang tidak ada variabel target untuk clustering. Sebaliknya, algoritma klasterisasi mencari ke segmen data seluruh set menjadi sub kelompok yang relatif homogen atau kelompok, di mana kesamaan catatan dalam cluster dimaksimalkan, dan kesamaan catatan luar klaster ini diminimalkan (Daniel t. Larose,2005).

Contoh tugas pengelompokan dalam bisnis dan penelitian meliputi :

1. Menentukan target pemasaran produk

2. Untuk tujuan audit akuntansi, melihat perilaku keuangan yang mencurigakan

3. Sebagai alat dimensi pengurangan ketika data set memiliki ratusan atribut

4. Untuk pengelompokan ekspresi gen, di mana jumlah yang sangat besar mungkin menunjukkan perilaku yang sama.

Pada analisis cluster ada beberapa hal yang harus diperhatikan, sebagai contoh, kita akan perlu menentukan:

1. Bagaimana mengukur kesamaan

2. Bagaimana recode variabel kategori 
3. Bagaimana standarisasi atau menormalkan variabel numerik

4. Berapa banyak cluster yang akan dibentuk

\subsection{Interval-skala variabel}

Interval-skala variabel adalah pengukuran kontinyu yang meliputi skala linier. Contoh, berat dan tinggi, lintang dan bujur dan suhu cuaca. Penggunaan unit pengukuran dapat mempengaruhi analisa cluster[8]. Sebagai contoh perubahan pengukuran dari meter ke inchi, atau dari kilogram ke pound, mungkin akan menghasilkan stuktur cluster yang sangat berbeda. Untuk itu diperlukan normalisasi data, agar semua data mempunyai bobot yang sama. Langkah langkah untuk normalisasi data yaitu :

1. Hitung nilai mean

$$
s f=\frac{1}{n}(\lfloor x 1 f-m f\rfloor+\lfloor x 2 f-m f\rfloor+\cdots .+\lfloor x n f-m f\rfloor)
$$

2. Hitung nilai z-score

$$
\text { zif }=\frac{x i f-m f}{s f}
$$

\subsection{Algorithma K-Means}

Algoritma k -means Clustering[1] adalah algoritma sederhana dan efektif untuk menemukan cluster dalam data dengan algoritma sebagai berikut:
Langkah 1
: Tentukan jumlah cluster
Langkah 2
: Tentukan nilai yang menjadi lokasi pusat cluster awal .
Langkah 3
: Hitung pusat cluster terdekat untuk setiap record
Langkah 4
: Untuk setiap cluster $\mathrm{k}$, hitung centroid cluster dan memperbarui
lokasi setiap pusat cluster

Langkah 5 : Ulangi langkah 3 sampai 5 sampai konvergensi atau penghentian .

Algorithma k-means dikenal dan banyak digunakan untuk metoda partitional, yaitu membagi himpunan objek data ke dalam sub himpunan cluster yang tidak saling tumpang tindih, sehingga setiap objek data tepat berada dalam satu cluster

\section{Hasil dan Pembahasan}

Data sumber yang digunakan pada penelitian ini adalah data yang berasal LPLPO

\begin{tabular}{|c|c|c|c|c|c|c|c|c|c|c|c|c|c|c|}
\hline \multicolumn{3}{|c|}{$\begin{array}{l}\text { REKAPITULASI RESEP } \\
\text { APOTEK } \\
\text { PUSKESMAS : RUMBAI BUKIT } \\
\text { BULAN } \quad \text { : JANUARI } \\
\text { TAHUN } \quad \text { : } 2014\end{array}$} & & & & & & & & & & & & \\
\hline \multirow{2}{*}{ No } & \multirow{2}{*}{ NAMA OBAT } & \multirow{2}{*}{ Satuan } & \multicolumn{12}{|c|}{ Bulan } \\
\hline & & & Jan & Feb & Maret & April & Mei & Juni & Juli & Agust & Sept & Okt & Nov & Des \\
\hline 1 & Acyclovir krim & tube & 4 & 5 & 4 & 21 & 23 & 15 & 19 & 19 & 24 & 24 & 91 & 75 \\
\hline 2 & Acyclovir $200 \mathrm{mg}$ & tablet & 20 & 110 & 20 & 95 & 110 & 132 & 23 & 0 & 0 & 0 & 0 & 0 \\
\hline 3 & Acyclovir $400 \mathrm{mg}$ & tablet & 10 & 0 & 0 & 488 & 0 & 0 & 210 & 100 & 200 & 195 & 220 & 115 \\
\hline 4 & Alat suntik $1 \mathrm{ml}$ & set & 0 & 0 & 0 & 0 & 0 & 0 & 0 & 0 & 100 & 0 & 0 & 0 \\
\hline 5 & Alat suntik $5 \mathrm{ml}$ & set & 0 & 0 & 0 & 0 & 0 & 0 & 0 & 0 & 0 & 0 & 100 & 0 \\
\hline 6 & Albendazol $400 \mathrm{mg}$ tab & tablet & 23 & 54 & 13 & 6 & 32 & 87 & 15 & 15 & 16 & 6 & 66 & 60 \\
\hline 7 & Alluporinol tab $100 \mathrm{mg}$ & tablet & 20 & 170 & 150 & 60 & 70 & 270 & 50 & 493 & 0 & 0 & 0 & 0 \\
\hline 8 & Ambroxol $30 \mathrm{mg}$ & tablet & 191 & 200 & 3028 & 225 & 127 & 72 & 120 & 20 & 149 & 340 & 1602 & 1035 \\
\hline 9 & Ambroxol sirup & botol & 72 & 56 & 57 & 45 & 28 & 22 & 50 & 30 & 193 & 0 & 0 & 0 \\
\hline 10 & Aminofilin tab $200 \mathrm{mg}$ & tablet & 10 & 0 & 152 & 0 & 72 & 10 & 0 & 0 & 40 & 0 & 45 & 33 \\
\hline
\end{tabular}
Puskesmas Rumbai Bukit tahun 2014. Adapun data yang digunakan dapat dilihat pada tabel 1. 
Terdapat 133 jenis obat pada apotik puskesmas rumbai bukit, adapun sebagian dari jenis obat dan pengeluaran obat tiap bulan dapat dilihat pada table berikut

Tabel 2. Rekapitulasi Obat Perbulan

\begin{tabular}{|c|c|c|c|c|c|c|c|c|c|c|c|c|c|c|}
\hline \multirow{2}{*}{ NO } & \multirow{2}{*}{ NAMA OBAT } & \multirow{2}{*}{ Satuan } & \multicolumn{12}{|c|}{ Bulan } \\
\hline & & & Jan & Feb & Maret & April & Mei & Juni & Juli & Agust & Sept & Okt & Nov & Des \\
\hline 1 & Acyclovir krim & tube & 4 & 5 & 4 & 21 & 23 & 15 & 19 & 19 & 24 & 24 & 91 & 75 \\
\hline 2 & Acyclovir $200 \mathrm{mg}$ & tablet & 20 & 110 & 20 & 95 & 110 & 132 & 23 & 0 & 0 & 0 & 0 & 0 \\
\hline 3 & Acyclovir $400 \mathrm{mg}$ & tablet & 10 & 0 & 0 & 488 & 0 & 0 & 210 & 100 & 200 & 195 & 220 & 115 \\
\hline 4 & Alat suntik $1 \mathrm{ml}$ & set & 0 & 0 & 0 & 0 & 0 & 0 & 0 & 0 & 100 & 0 & 0 & 0 \\
\hline 5 & Alat suntik $5 \mathrm{ml}$ & set & 0 & 0 & 0 & 0 & 0 & 0 & 0 & 0 & 0 & 0 & 100 & 0 \\
\hline 6 & $\begin{array}{l}\text { Albendazol } 400 \mathrm{mg} \\
\text { tab }\end{array}$ & tablet & 23 & 54 & 13 & 6 & 32 & 87 & 15 & 15 & 16 & 6 & 66 & 60 \\
\hline 7 & $\begin{array}{l}\text { Alluporinol tab } 100 \\
\text { mg }\end{array}$ & tablet & 20 & 170 & 150 & 60 & 70 & 270 & 50 & 493 & 0 & 0 & 0 & 0 \\
\hline 8 & Ambroxol $30 \mathrm{mg}$ & tablet & 191 & 200 & 3028 & 225 & 127 & 72 & 120 & 20 & 149 & 340 & 1602 & 1035 \\
\hline 9 & Ambroxol sirup & botol & 72 & 56 & 57 & 45 & 28 & 22 & 50 & 30 & 193 & 0 & 0 & 0 \\
\hline 10 & $\begin{array}{l}\text { Aminofilin tab } 200 \\
\text { mg }\end{array}$ & tablet & 10 & 0 & 152 & 0 & 72 & 10 & 0 & 0 & 40 & 0 & 45 & 33 \\
\hline 11 & $\begin{array}{l}\text { Amoksisilin tab } \\
250 \mathrm{mg}\end{array}$ & kapsul & $\begin{array}{c}102 \\
0\end{array}$ & 924 & 844 & 660 & 750 & 1456 & 1344 & 780 & 1142 & 1308 & 2002 & 1474 \\
\hline 12 & $\begin{array}{l}\text { Amoksisilin cap } \\
500 \mathrm{mg}\end{array}$ & kapsul & $\begin{array}{c}224 \\
5\end{array}$ & 2310 & 2370 & 1780 & 1503 & 1765 & 1795 & 1210 & 4340 & 2110 & 2754 & 2042 \\
\hline 13 & $\begin{array}{l}\text { Amoksisilin syr } \\
\text { kering } 125 \mathrm{mg}\end{array}$ & botol & 110 & 110 & 77 & 83 & 96 & 166 & 162 & 91 & 145 & 161 & 193 & 150 \\
\hline 14 & $\begin{array}{l}\text { Amlodipin besilat } \\
10 \mathrm{mg}\end{array}$ & tablet & 150 & 130 & 180 & 550 & 755 & 200 & 20 & 40 & 371 & 90 & 400 & 110 \\
\hline 15 & Antasida tab doen & tablet & 912 & 2147 & 1023 & 1090 & 1098 & 1145 & 990 & 268 & 529 & 693 & 2030 & 1724 \\
\hline 16 & $\begin{array}{l}\text { Antasida doen } \\
\text { suspensi }\end{array}$ & botol & 37 & 29 & 22 & 37 & 18 & 13 & 49 & 44 & 100 & 62 & 60 & 45 \\
\hline 17 & $\begin{array}{l}\text { Anti bakteri doen } \\
\text { salap }\end{array}$ & tube & 14 & 21 & 20 & 15 & 10 & 19 & 24 & 7 & 12 & 17 & 35 & 25 \\
\hline ….. & n........ & $\ldots \ldots \ldots$ & $\cdots$ & & $\ldots \ldots$ & & & & & & & & & \\
\hline & ......... & $\ldots$ & & & $\cdots$ & & & & & & & & & \\
\hline 133 & Loperamid & & 94 & 122 & 128 & 20 & 0 & 0 & 0 & 0 & 0 & 0 & 0 & 0 \\
\hline
\end{tabular}

Dari data diatas (tabel 2) selanjutnya dilakukan proses normalisasi data agar data mempunyai rentang nilai yang lebih kecil sehingga dapat mempercepat dalam proses perhitungan normalisasi, pada penelitian ini digunakan normalisasi z-score. Sebagian hasil normalisasi dapat dilihat pada table 3 .

Tabel 3. Hasil normalisasi dengan z-score

\begin{tabular}{|c|c|c|c|c|c|c|c|c|c|}
\hline 0.0000 & 0.0000 & 0.0004 & 0.0021 & 0.0023 & 0.0015 & 0.0019 & 0.0019 & 0.0024 & 0.0024 \\
\hline 0.0091 & 0.0075 & & & & & & & & \\
\hline 0.0000 & 0.0000 & 0.0020 & 0.0095 & 0.0110 & 0.0132 & 0.0023 & 0 & 0 & 0 \\
\hline
\end{tabular}




\begin{tabular}{|c|c|c|c|c|c|c|c|c|c|}
\hline 0.0000 & 0 & 0 & 488 & 0 & 0.0210 & 0.0100 & 0.0200 & 0.0195 & \\
\hline 0115 & & & & & & & & & \\
\hline 0 & 0 & 0 & 0 & 0 & 0 & .0100 & $\begin{array}{ll}0 & 0\end{array}$ & 0 & \\
\hline 0 & 0 & 0 & 0 & $\begin{array}{ll}0 & 0\end{array}$ & 0 & $\begin{array}{ll}0 & 0\end{array}$ & $\begin{array}{ll}0 & 0.0100\end{array}$ & 0 & \\
\hline 0.0000 & 0.0000 & 0.0013 & 0.0006 & 0.0032 & 0.0087 & 0.0015 & 0.0015 & 0.0016 & 0.0006 \\
\hline 0066 & 0.0060 & & & & & & & & \\
\hline 0.0000 & 0.0000 & 0.0150 & 0.0060 & 0.0070 & 0.0270 & 0.0050 & 0.0493 & 0 & 0 \\
\hline & & & & & & & & & \\
\hline 0.00 & 0.0000 & 0.3028 & 0.0225 & 0.0127 & 0.0072 & 0.0120 & 0.0020 & 0.0149 & 0.0340 \\
\hline 1602 & 0.1035 & & & & & & & & \\
\hline 0.0000 & 0.0000 & 0.0057 & 0.0045 & 0.0028 & 0.0022 & 0.0050 & 0.0030 & 0.0193 & \\
\hline & & & & & & & & & \\
\hline 0.0000 & 0 & 0.0152 & 0 & .0072 & .0010 & 0 & 0.0040 & 0 & 0.0045 \\
\hline 0033 & & & & & & & & & \\
\hline 0.0003 & 0.0002 & 0.0844 & 0.0660 & 0.0750 & 0.1456 & 0.1344 & 0.0780 & 0.1142 & 0.1308 \\
\hline 2002 & 0.1474 & & & & & & & & \\
\hline 0.0006 & 0.0005 & 0.2370 & 0.1780 & 0.1503 & 0.1765 & 0.1795 & 0.1210 & 0.4340 & 0.2110 \\
\hline .2754 & 0.2042 & & & & & & & & \\
\hline 0.0000 & 0.0000 & 0.0077 & 0.0083 & 0.0096 & 0.0166 & 0.0162 & 0.0091 & 0.0145 & 0.0161 \\
\hline 0193 & 0.0150 & & & & & & & & \\
\hline 0.0000 & 0.0000 & 0.0180 & 0.0550 & 0.0755 & 0.0200 & 0.0020 & 0.0040 & 0.0371 & 0.0090 \\
\hline 0400 & 0.0110 & & & & & & & & \\
\hline 0.0002 & 0.0005 & 0.1023 & 0.1090 & 0.1098 & 0.1145 & 0.0990 & 0.0268 & 0.0529 & 0.0693 \\
\hline 2030 & 0.1724 & & & & & & & & \\
\hline 0.0000 & 0.0000 & 0.0022 & 0.0037 & 0.0018 & 0.0013 & 0.0049 & 0.0044 & 0.0100 & 0.0062 \\
\hline .0060 & 0.0045 & & & & & & & & \\
\hline 0.0000 & 0.0000 & 0.0020 & 0.0015 & 0.0010 & 0.0019 & 0.0024 & 0.0007 & 0.0012 & 0.0017 \\
\hline .0035 & 0.0025 & & & & & & & & \\
\hline 0.0000 & 0.0000 & 0.0014 & 0.0014 & 0.0021 & 0.0014 & 0 & 0 & 0 & 0 \\
\hline & & & & & & & & & \\
\hline 0 & .0000 & .0128 & .0020 & 0 & U & U & 0 & 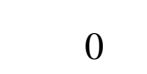 & 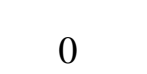 \\
\hline
\end{tabular}

Tahap berikutnya ditentukan jumlah cluster yakni sebanyak 3 cluster, untuk dapat menentukan apakah suatu permintaan obat mempunyai permintaan "sangat tinggi", "tinggi", atau "kurang". Untuk nilai centroid awal dipilih secara acak. Nilai centroid diambil dari baris 50,60 dan 70 .

Iterasi 1 (tabel 3).

Pada langkah ini, pembaruan pusat pusat kelompok akan dilakukan sebagai berikut

Tabel 4. nilai centroid awal

\begin{tabular}{|l|l|l|l|l|l|l|l|l|l|l|l|l|}
\hline 0.0157 & 0.0045 & 2.0000 & 1.0000 & 1.0000 & 2.0000 & 1.0000 & 1.0000 & 2.0000 & 2.0000 & 0 & 13.0000 \\
\hline 0 & 0 & 0 & 0 & 0 & 0 & 0 & 0 & 0 & 0 & 0 & 200.0000 \\
\hline 0 & 0 & 0 & 10.0000 & 0 & 0 & 0 & 0 & 0 & 230.0000 & 145.0000 & 0 \\
\hline
\end{tabular}

Selanjutnya dilakukan proses clustering d0 (tabel 4). Dari hasil clustring setelah 3 kali iterasi didapat hasil pengelompokkan data obat, yang dikelompokkan jadi 3 kelompok yaitu kelompok permintaan obat sangat tinggi, kelompok obat dengan permintaan tinggi dan kelompok permintaan obat yang tergolong kurang. Adapun jumlah hasil clustering dapat dilihat pada table berikut. 
Gambar 4. Clustering 1

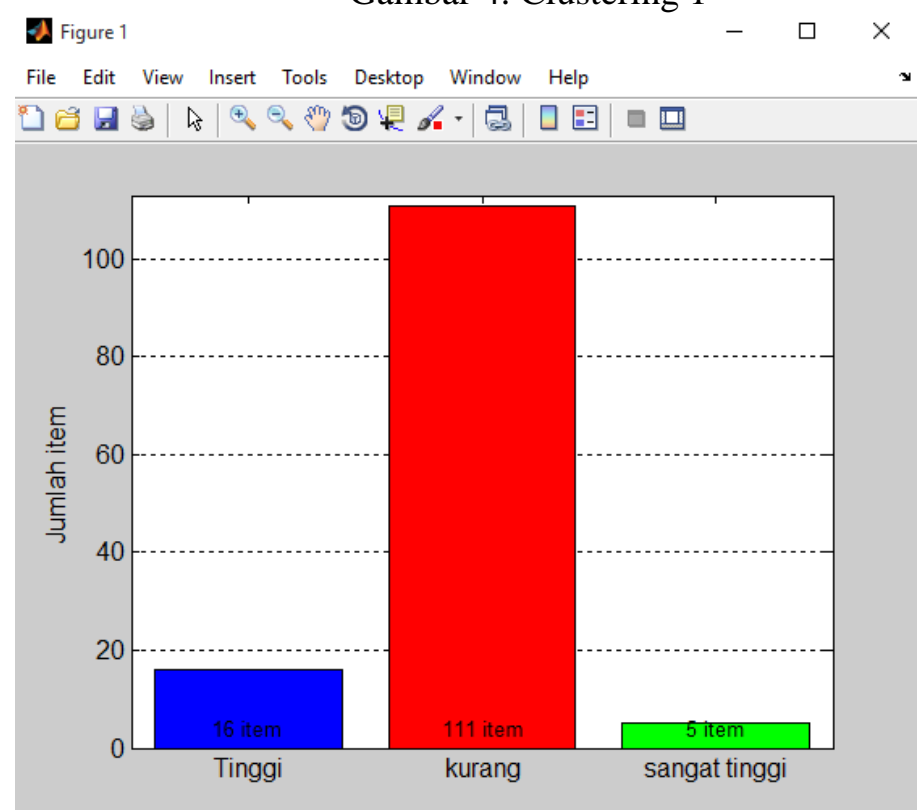

Sedangkan sebagian rincian table clustering data obat dapat dilihat pada table berikut.

Tabel 4. Hasil Clustering Permintaan obat

\begin{tabular}{|r|l|r|r|r|r|r|r|r|r|r|r|r|r|r|}
\hline 1 & Acyclovir krim & tube & 4 & 5 & 4 & 21 & 23 & 15 & 19 & 19 & 24 & 24 & 91 & 75 \\
\hline 2 & $\begin{array}{l}\text { Acyclovir } 200 \\
\text { mg }\end{array}$ & tablet & 20 & 110 & 20 & 95 & 110 & 132 & 23 & 0 & 0 & 0 & 0 & 0 \\
\hline 3 & $\begin{array}{l}\text { Acyclovir 400 } \\
\text { mg }\end{array}$ & tablet & 10 & 0 & 0 & 488 & 0 & 0 & 210 & 100 & 200 & 195 & 220 & 115 \\
\hline 4 & Alat suntik 1 ml & set & 0 & 0 & 0 & 0 & 0 & 0 & 0 & 0 & 100 & 0 & 0 & 0 \\
\hline 5 & Alat suntik 5 ml & set & 0 & 0 & 0 & 0 & 0 & 0 & 0 & 0 & 0 & 0 & 100 & 0 \\
\hline 6 & $\begin{array}{l}\text { Albendazol 400 } \\
\text { mg tab }\end{array}$ & tablet & 23 & 54 & 13 & 6 & 32 & 87 & 15 & 15 & 16 & 6 & 66 & 60 \\
\hline 7 & $\begin{array}{l}\text { Alluporinol tab } \\
\text { 100 mg }\end{array}$ & tablet & 20 & 170 & 150 & 60 & 70 & 270 & 50 & 493 & 0 & 0 & 0 & 0 \\
\hline 8 & Ambroxol 30 mg & tablet & 191 & 200 & 3028 & 225 & 127 & 72 & 120 & 20 & 149 & 340 & 1602 & 1035 \\
\hline 9 & Ambroxol sirup & botol & 72 & 56 & 57 & 45 & 28 & 22 & 50 & 30 & 193 & 0 & 0 & 0 \\
\hline 10 & $\begin{array}{l}\text { Aminofilin tab } \\
\text { 200 mg }\end{array}$ & tablet & 10 & 0 & 152 & 0 & 72 & 10 & 0 & 0 & 40 & 0 & 45 & 33 \\
\hline 11 & $\begin{array}{l}\text { Amoksisilin tab } \\
\text { 250 mg }\end{array}$ & kapsul & 1020 & 924 & 844 & 660 & 750 & 1456 & 1344 & 780 & 1142 & 1308 & 2002 & 1474 \\
\hline 12 & $\begin{array}{l}\text { Amoksisilin cap } \\
\text { 500 mg }\end{array}$ & kapsul & 2245 & 2310 & 2370 & 1780 & 1503 & 1765 & 1795 & 1210 & 4340 & 2110 & 2754 & 2042 \\
\hline 13 & $\begin{array}{l}\text { Amoksisilin syr } \\
\text { kering 125 mg }\end{array}$ & botol & 110 & 110 & 77 & 83 & 96 & 166 & 162 & 91 & 145 & 161 & 193 & 150 \\
\hline 14 & $\begin{array}{l}\text { Amlodipin } \\
\text { besilat 10 mg }\end{array}$ & tablet & 150 & 130 & 180 & 550 & 755 & 200 & 20 & 40 & 371 & 90 & 400 & 110 \\
\hline 15 & $\begin{array}{l}\text { Antasida tab } \\
\text { doen }\end{array}$ & tablet & 912 & 2147 & 1023 & 1090 & 1098 & 1145 & 990 & 268 & 529 & 693 & 2030 & 1724 \\
\hline 16 & $\begin{array}{l}\text { Antasida doen } \\
\text { suspensi }\end{array}$ & botol & 37 & 29 & 22 & 37 & 18 & 13 & 49 & 44 & 100 & 62 & 60 & 45 \\
\hline
\end{tabular}




\begin{tabular}{|c|l|r|r|r|r|r|r|r|r|r|r|r|r|r|}
\hline 17 & $\begin{array}{l}\text { Anti bakteri doen } \\
\text { salap }\end{array}$ & tube & 14 & 21 & 20 & 15 & 10 & 19 & 24 & 7 & 12 & 17 & 35 & 25 \\
\hline 18 & $\begin{array}{l}\text { Anti fungi doen } \\
\text { salep }\end{array}$ & pot & 15 & 44 & 14 & 14 & 21 & 14 & 0 & 0 & 0 & 0 & 0 & 0 \\
\hline 19 & $\begin{array}{l}\text { Anti hemoroid } \\
\text { supp komb }\end{array}$ & supp & 0 & 0 & 0 & 0 & 0 & 13 & 16 & 0 & 3 & 0 & 8 & 0 \\
\hline 20 & $\begin{array}{l}\text { Asam askorbat } \\
\text { tab 50 mg }\end{array}$ & tablet & 1419 & 3812 & 3783 & 3005 & 2784 & 3392 & 3890 & 2703 & 3955 & 3567 & 7090 & 6112 \\
\hline 21 & $\begin{array}{l}\text { Asam mefenamat } \\
\text { tab 500 mg }\end{array}$ & kaplet & 800 & 940 & 1040 & 1032 & 930 & 1000 & 570 & 420 & 820 & 715 & 1708 & 1510 \\
\hline
\end{tabular}

\section{Kesimpulan}

Dari hasil clusterisasi data obat dapat disimpulkan bahwa banyak diantara obat yang ada masuk dalam kelompok cluster kurang. Kecendrungan obat yang tergolong kurang ini adalah ada beberapa bulan yang tidak ada permintaan sama sekali terhadap obat tersebut. Sedangkan kelompok obat yang termasuk tinggi rata rata permintaan obatnya setiap bulan diatas 300 buah, sedangkan obat yang masuk dalam kelompok cluster sangat tinggi rata rata permintaan setiap bulannya adalah diatas 2000 buah. Dari hasil analisa cluster diatas mungkin perlu dilakukan lagi penelitian lanjutan agar clusterisasi data obat dapat dilakukan secara lebih valid dengan menetapkan nilai centroid terbaik.

\section{Daftar Pustaka}

[1] Tipawan.S and Kulthida.T "Data mining and its application for knowladge management : a literature review from 2007 to 2012 " (2012)

[2] Hans-Peter .K, Karsten, Peer.K, Alexey.P, Matthias.S, Arthur.Z, "Future trends in data mining" (2007)

[3] J.Ranjan "Application of data mining techniques in pharmaceutical industry" (2007)

[4] K.Arai and A.R. Barakbah "Hierarchical K-means : and algorithm for centroids initialization for K-means".(2007)

[5] Usama Fayyad, Gregory Piatetsky-Shapiro, and Padhraic Smyth "From Data Mining to Knowledge Discovery in Databases" (1996)

[6] Daniel t. larose "Discovering knowledge in data an Introduction to Data Mining", John Wiley \& Sons 2005 